
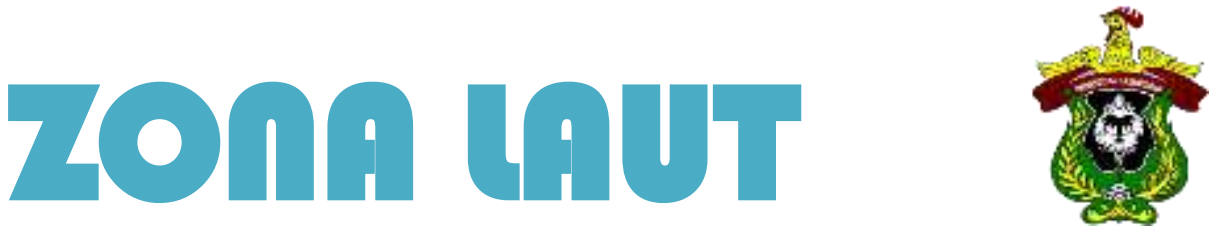

\title{
ANALISA TAHANAN DAN DAYA MESIN PADA KAPAL MINI LNG BERBASIS SIMULASI NUMERIK
}

\author{
*Kusnindar Priohutomo, Endah Suwarni dan Cakra Wijaya \\ Balai Teknologi Hidrodinamika, BPPT \\ *kusnindar.priohutomo@gmail.com
}

\begin{abstract}
Abstrak
Kebutuhan akan kapal Mini LNG (small LNG carrier) di Indonesia semakin meningkat seiring dengan meningkatnya kebutuhan pasokan LNG dari LNG field ke pulau-pulau di Indonesia bagian timur. Distribusi LNG ke pulau-pulau di Indonesia bagian timur kurang efektif bila menggunakan kapal LNG yang berukuran besar karena tidak adanya infrastruktur pipa gas untuk menyalurkan LNG dari terminal LNG di pelabuhan ke pengguna. Dengan kapal mini LNG maka pendistibusian LNG bisa menggunakan tangki-tangki LNG kecil yang nantinya akan dibawa oleh kendaraan darat setelah kapal bersandar di pelabuhan. Untuk mendesain sebuah kapal mini LNG diperlukan berbagai macam perhitungan yang tepat agar nantinya kapal yang dibangun akan memiliki performa yang baik dan efisien. Salah satunya yang harus dihitung adalah tahanan kapal dan EHP serta BHP untuk memprediksi daya mesin yang akan dipasang. Pada paper ini kajian difokuskan pada perhitungan tahanan kapal dan EHP serta BHP menggunakan metode simulasi numerik. Hasil dari paper ini untuk tahanan kapal desain 1 sebesar $101.01 \mathrm{kN}$ dan untuk desain 2 sebesar $267.06 \mathrm{kN}$. Pada desain 1 untuk EHP sebesar $519.93 \mathrm{~kW}$ dan BHP sebesar $611.68 \mathrm{~kW}$, sedangkan untuk desain 2 EHP sebesar $1373.87 \mathrm{~kW}$ dan BHP sebesar $1616.33 \mathrm{~kW}$.
\end{abstract}

Kata Kunci: Kapal Mini LNG, Tahanan Kapal, Effective Horsepower (EHP), Brake Horsepower (BHP), Simulasi Numeric, Orca 3D.

\begin{abstract}
Abstrct
The demand for small LNG carriers in Indonesia is increasing along with the increasing demand for LNG supply from the LNG field to the islands in eastern Indonesia. The distribution of LNG to islands in eastern Indonesia is not efficient if using a larger LNG carrier because in the islands there is no gas pipeline infrastructure to distribute LNG from the LNG terminal at the port to the user. With a small LNG carrier, the distribution LNG can use a small LNG tank that will be taken by land vehicles after the ship rests at the port. To design a small LNG ship, various calculations are needed so that the ship being built will have a good and efficient performance. One of them that must be calculated is the ship's resistance and engine power to be installed. In this paper the prediction of ship resistance and EHP BHP for prediction power of engine using numerical simulation methods. The results of this paper are for ship resistance at design 1 of $101.01 \mathrm{kN}$ and for design 2 of $267.06 \mathrm{kN}$. In design 1 for EHP of $519.93 \mathrm{~kW}$ and BHP of $611.68 \mathrm{~kW}$, and in design 2 EHP of $1373.87 \mathrm{~kW}$ and BHP of $1616.33 \mathrm{~kW}$.
\end{abstract}

Keyword: Mini LNG Ship, Ship Resistance, Effective Horsepower (EHP), Brake Horsepower (BHP), Numerical Simulation; Orca $3 D$.

\section{PENDAHULAN}

Small scale LNG Carrier atau small LNG tanker adalah kapal yang digunakan untuk mengangkut gas alam cair (LNG) dalam jumlah tidak terlalu banyak. Kapal jenis ini digunakan untuk wilayah dimana belum atau tidak ada saluran pipa gas, atau wilayah yang dari sisi ekonomis atau teknis yang tidak memungkinkan untuk dibangun instalasi saluran pipa gas [1]. Kata "small" atau "kecil" berdasarkan pada volume angkut LNG (dan ukuran kapal) maksimum hanya sampai 40.000 cbm (meter kubik). Kapal LNG Carrier biasa umumnya copyright is published under Lisensi Creative Commons Atribusi 4.0 Internasional. 
mampu mengangkut LNG dengan kapasitas 120.000 - $270.000 \mathrm{cbm}$ dan berlayar antar benua (seagoing ship) dengan waktu layar lebih dari 1 minggu. Sementara untuk kapal small LNG digunakan untuk berlayar sekitar 1000 mll laut dengan waktu layar 3 - 4 hari. Kapal small atau mini LNG di Indonesia belum terlalu banyak yang beroperasi, dari beberapa kapal tersebut terdapat milik PT. Humpuss Intermoda Transportasi dengan kapal "Surya Satsuma" yang memiliki panjang $151 \mathrm{~m}$, lebar $28 \mathrm{~m}$ dengan draft $7.02 \mathrm{~m}$. Kapal ini mampu mengangkut LNG berkapasitas $22.500 \mathrm{cbm}$.

Badan Pengkajian dan Penerapan Teknologi (BPPT) memiliki program Inovasi Teknologi Alat Angkut Maritim dimana salah satu didalamnya adalah men-desain kapal Mini LNG untuk perairan Indonesia. Kapal ini diharapkan mampu untuk berlayar di seluruh perairan Indonesia mulau dari ujung barat dampai ujung timur Indonesia. Untuk itu diperlukan kajian desain yang memiliki tingkat keakurasian tinggi mulai dari bentuk lambung kapal, sistem propulsi kapal, sistem peng-angkut LNG, sistem kelistrikan dan lain-lain Untuk dapet mendesain sebuah kapal yang mampu beroperasi dengan baik maka literature atau tinjuan pustaka yang digunakan harus mengakomodasi berbagai sumber pengetahuan. Untuk saat ini banyak yang menggunakan bantuan program numeric untuk mendapatkan data karakterisitik hidrodinamika kapal antara lain tahanan kapal. Metode ini dinamakan metode Computational Fluid Dynamics (CFD). Untuk memastikan apakah metode nuemrik menggunakan CFD dapat membantu dalam mendesain kapal maka tinjuan pustaka difokuskan pada paper yang membahas tentang metode numeric menggunakan CFD antara lain paper penelitian yang dilakukan oleh [2]. Dimana pada paper ini membahas tentang pengujian model kapal tanker yang diberi penambahan berupa sirip (wavefoil) pada bagian bow dengan tujuan untuk mengurangi tahanan kapal (resistence) dan olah gerak kapal (motion) pada saat kapal berlayar. Pendekatan yang dilakukan adalah dengan melakukan perbandingan antara hasil pengujian model dengan hasil simulasi numerik berbasis timedomain simulations. Gaya yang mengenai wavefoil dihitung menggunakan model slightly-modified Leishman-Beddoes. Pengujian dilakukan menggunakan model dengan skala 1:16.57 dengan desain dari Rolls-Royce Marine. Pengujian dilakukan di MARINTEK Towing Tank Norway. Untuk simulasi numeric menggunakan VeSim dari Norwegian University of Science and Technology. Dari penelitian yang dilakukan didaptkan hasil dengan menambahkan wavefoil pada bagian depan kapal maka tahanan kapal berkurang 9$17 \%$ pada saat menghadapi gelombang dari depan (head seas), sedangkan untuk heave dan pitch berkurang antara 11-25\%. Penelitian lain yand dilakukan oleh [3]. Didalam paper ini membahas tentang penggunaan software CFD didalam menganalisa tahanan kapal (resistance). Pendekatan metode CFD ini bertumpu pada persamaan Reynolds Averaged Navier Stokes (RANS). Pada paper ini juga menunjukkan komponen yang mempengaruhi tahanan kapal pada berbagai bentuk kapal yang dianalisa menggunakan pendekatan CFD. Cara melakukan extrapolasi resistance model kapal juga berpengaruh terhadap hasil perhitungan tahanan pada kondisi full scale. Extrapolasi tahanan kapal dibedakan menjadi dua metode yaitu metode 2D yang dikembangkan oleh Froude dan metode 3D yang dikembangkan oleh Hughes. Masing-masing metode memiliki kelebihan dan kekurangan. Hasil dari paper ini adalah besaran ketidakpastian dari perhitungan CFD model scale yang dikonversikan ke full scale tergantung dari pendekatan yang dipilih.

Penelitian berikutnya dilakukan [4], yang pada papernya membahas tentang gerakan kapal yang dipengaruhi oleh sloshing akibat cairan yang termuat didalam kapal pada berbagai kondisi. Solusi potential flow untuk motion kapal menggunakan boundary element method (BEM) berbasis Green's function, sementara untuk solusi permasalahan sloshing menggunakan finite volume method (FVM) berbasis multiphase interface capturing volume of fluid $(\mathrm{VoF})$ teknik. Validasi dilakukan menggunakan metode experiment. Hasil dari paper ini adalah pentingnya untuk mengetahui efek dari sloshing coupling pada contoh kasus kapal LNG FSPO. Dimana dari hasil penelitian ini diketahui bahwa tekanan pada lambung kapal yang disebabkna oleh pergerakan kapal tanpa memperhatikan efek dari sloshing menyebakan over estimasi dibandingkan dengan perhitungan yang memasukkan efek dari sloshing. Paper berikutnya yang membahas tentang penggunaan aplikasi CFD dilakukan oleh [5], membahas tentang studi kelayakan dalam hal desain kapal hisap tambang, dimana pada tahapan ini perhitungan gaya-gaya yang bekerja pada lambung kapal dapat diketahui dan dianalisa apakah masih didalam toleransi yang di-ijinkan oleh International Maritime Organization (IMO) dan Biro Klasifikasi Indonesia (BKI). Studi kelayakan ini difokuskan pada analisa stabilitas dan tegangan geser yang bekerja pada kapal. Metode numerik digunakan pada paper ini melalui software Ansys Mechanical. Berdasarkan paper ini didapatkan kesimpulan bahwa pada kondisi load case, angle of minimum (GZ) kurang dari standar yang ditetapkan oleh IMO yaitu 25 derajat. Sedangkan shear stress pada berbagai kondisi load case masih memenuhi criteria yang ditetapkan oleh BKI yaitu kurang dari $100 \mathrm{MPa}$.

Paper berikutnya yang juga merupakan literature penting yaitu paper yang ditulis oleh [6] dimana dijelaskan pada paper ini diperlukan kapal LNG untuk mengangkut LNG yang dihasilkan di Blok Masela dimana blok Masela memiliki cadangan sebesar 10,73 trillion cubic feet (TCF). Dengan dioperasikannya kilang terapung 
(FLNG) maka diperlukan alat transportasi berupa kapal LNG untuk mempermudah pendistribusian LNG ke berbagai wilayah. Perancangan kapal menggunakan software Maxsurf dan Rhineceros untuk pemodelan dan analisa karakterisktik kapal. Ukuran utama kapal pada paper ini adalah LPP $=99 \mathrm{~m}, \mathrm{~B}=17,2 \mathrm{~m}, \mathrm{H}=10,92$ $\mathrm{m}, \mathrm{T}=5,5 \mathrm{~m}$ dan memiliki displacement 7256 ton. Dari hasil perhitungan didapatkan untuk tahana kapal sebesar 166,4 kN dan daya mesin sebesar $1493 \mathrm{HP}$, dimana kapal memiliki stabilitas yang baik sesuai standar dari IMO.Dari beberapa literature tersebut, maka penulis melakukan kajian hidrodinamika desain kapal Mini LNG dengan berfokus kepada prediksi tahanan kapal (resistance) dan kebutuhan daya mesin penggerak kapal yang disimbolkan dengan EHP dan BHP. Metode yang digunakan pada perhitungan prediksi tahanan dan EHP serta BHP kapal adalah metode numerik dengan menggunakan software Rhinoceros dan Orca 3D.

\section{METODE}

Metodologi penelitian digunakan untuk memperjelas langkah-langkah yang dikerjakan pada suatu penelitian. Pada paper ini metodologi penelitian dibagi menjadi beberapa bagian antara lain:

\subsection{Dimensi Utama Kapal}

Tahap pertama yang harus ditentukan dalam hal desain kapal adalah ukuran utama kapal. Pada paper ini terdapat dua jenis desain kapal Mini LNG yang memiliki perbedaan dari bentuk lambung dan kegunaan dari kapal itu sendiri. Untuk sarat kapal pada desain ini dibuat satu sarat yaitu sarat muatan penuh (full load). Ukuran utama kapal Mini LNG desain 1 dan desain 2 ditampilkan pada tabel 1 dan table 2.

Tabel 1. Ukuran utama kapal Mini LNG desain 1

\begin{tabular}{lll}
\hline Keterangan & Ukuran & Unit \\
\hline Panjang (LOA) & 49.2 & $\mathrm{~m}$ \\
Panjang (LBP) & 45.7 & $\mathrm{~m}$ \\
Lebar (B) & 11.4 & $\mathrm{~m}$ \\
Tinggi $(\mathrm{H})$ & 6.0 & $\mathrm{~m}$ \\
Sarat Full Load $(\mathrm{T} 1)$ & 2.5 & $\mathrm{~m}$ \\
Displacement $(\Delta)$ & 1081.7 & ton \\
\hline
\end{tabular}

Tabel 2. Ukuran utama kapal Mini LNG desain 2

\begin{tabular}{lll}
\hline Keterangan & Ukuran & Unit \\
\hline Panjang (LOA) & 95.9 & $\mathrm{~m}$ \\
Panjang (LBP) & 91.7 & $\mathrm{~m}$ \\
Lebar (B) & 20.7 & $\mathrm{~m}$ \\
Tinggi $(\mathrm{H})$ & 9.0 & $\mathrm{~m}$ \\
Sarat Full Load $(\mathrm{T} 1)$ & 3.8 & $\mathrm{~m}$ \\
Displacement $(\Delta)$ & 5765.6 & ton \\
\hline
\end{tabular}

\subsection{Rencana Garis (Lines Plan)}

Dari dimensi utama kapal yang sudah ditentukan, langkah selanjutnya adalah penggambaran rencana garis kapal (lines plan). Gambar rencana garis adalah gambar desain kapal yang berisi informasi utama kapal antara lain panjang, lebar, tinggi dan sarat. Gambar ini berupa garis-garis irisan kapal yang dinamakan station, buttock dan waterline. Pembuatan rencana garis dilakukan dengan software gambar Rhinoceros. Gambar rencana garis untuk kapal Mini LNG desain 1 ditampilkan pada gambar 1 sedangkan untuk kapal mini LNG desain 2 ditampilkan pada gambar 2. 

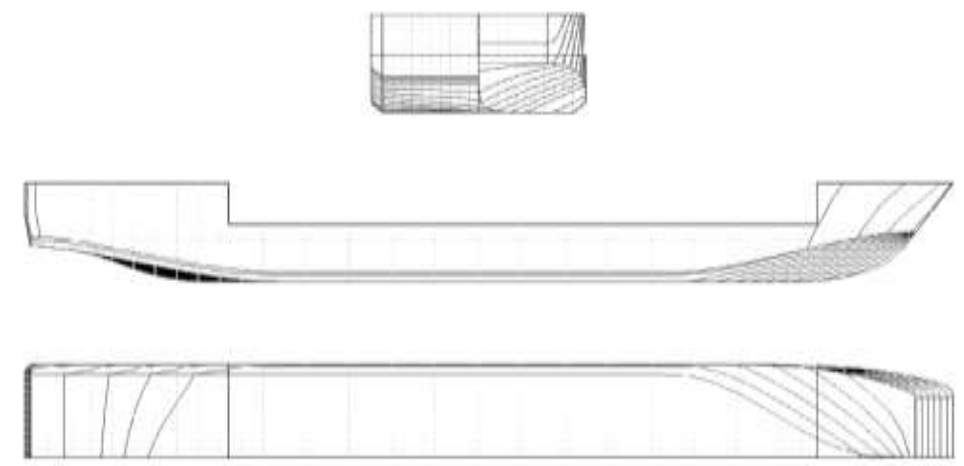

Gambar 1. Lines Plan Kapal Mini LNG desain 1
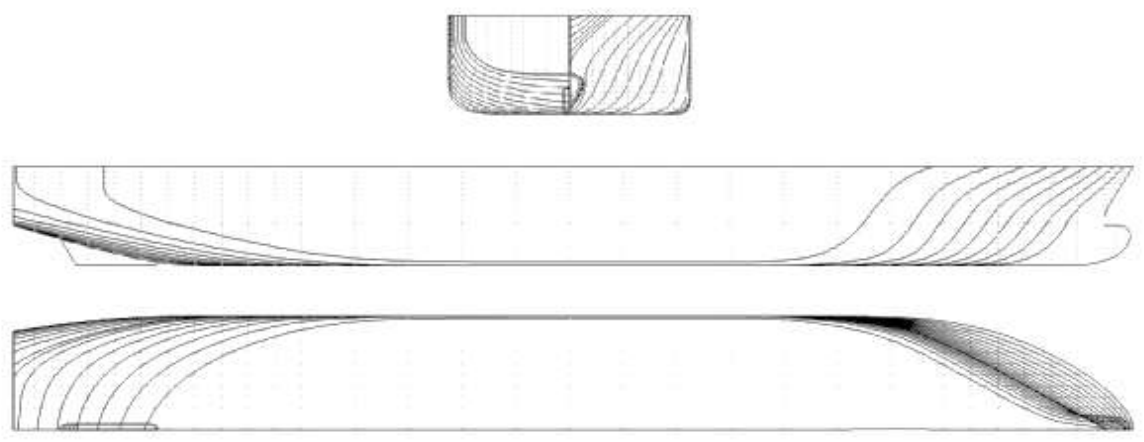

Gambar 2. Lines Plan Kapal Mini LNG desain 2

\subsection{Prediksi Tahanan Dan Propulsi Kapal Berbasis Simulasi Numerik}

Prediksi perhitungan tahanan dan propulsi kapal Mini LNG dilakukan menggunakan simulasi numerik, dimana untuk simulasi numerik menggunakan software Orca 3D. Orca 3d adalah software plugin dari Rhinoceros yang memiliki spesialisasi dibidang teknik perkapalan (naval architecture). Setelah dilakukan pembuatan model 3D kapal maka dapat dilakukan analisa hydrostatic, stability dan speed/power prediction menggunakan software Orca 3D. Untuk paper ini analisa prediksi tahanan kapal dan daya efektif kapal dilakukan menggunakan metode yang dikemukakan oleh [7], dimana hasil analisa dari Orca 3D untuk analisa tahanan dihasilkan beberapa output antara lain:

1. Froude number (Fn)

Dasar perhitungan Froude number (Fn) yang tercantum pada buku (Lewis, 1988) dapat dihitung menggunakan persamaan:

$$
F n=\frac{V}{\sqrt{g \times L W L}}
$$

Dengan $\mathrm{V}$ adalah kecepatan kapal $(\mathrm{m} / \mathrm{s})$, g adalah gaya gravitasi $\left(\mathrm{m} / \mathrm{s}^{2}\right)$, LWL adalah panjang garis air $(\mathrm{m})$.

2. Koefisien tahanan friksi (Cf)

Untuk koefisien tahanan friksi (Cf) dalam buku (Lewis, 1988) diatur juga persamaan yang dapat dihitung adalah:

$$
C f=\frac{0.075}{\log 10 R e-2^{2}}
$$

Dengan Cf adalah koefisien tahanan friksi dan Re adalah reynolds number. 
3. Perhitungan tahanan kapal (Rt)

Perhitungan tahanan total kapal menurut jurnal yang dikeluarkan oleh (ITTC, 2017) menyatakan bahwa perhitungan tahanan kapal dapat menggunakan persamaan:

$$
R t=\frac{1}{2} x \rho x v^{2} x \operatorname{Stot} x[C f+C a]+R w x W
$$

Dengan $\rho$ adalah massa jenis air laut.

4. Efektif Horse Power (EHP)

Efektif horse power adalah kebutuhan daya untuk mengatasi gaya hambat dari badan kapal (hull), agar kapal daapt bergerak dari satu tempat ke tempat yang lain dengan kecepatan servis sebesar Vs. Daya efektif ini merupakan fungsi dari besarnya gaya hambat total dan kecepatan kapal. Perhitungan daya efektif pada kapal ada beberapa metode, salah satunya menurut (Holtrop and Mennen, 1982) dengan menggunakan persamaan:

$$
E H P=R t x v
$$

Dengan Rt adalah tahanan total kapal (N) dan Vadalah kecepatan kapal $\left(\mathrm{m} / \mathrm{s}^{2}\right)$

5. Delivery Horse Power (DHP)

Deliverd horse power adalah besarnya daya yang dihasilkan dari pengurangan EHP dengan koefisien propulsi $(\mathrm{Pc})$, dimana Pc dapat dihitung dengan menggunakan persamaan:

$$
P c=\operatorname{pr} \times \eta 0 \times \eta H
$$

Dengan nilai $\eta r r, ~ \eta 0$, dan $\eta \mathrm{H}$ masing-masing 1.05, 50\% dan 1.1127.

Sehingga:

$$
\mathrm{DHP}=\mathrm{EHP} / \mathrm{Pc}
$$

6. Shaft Horse Power (SHP)

Untuk jenis-jenis kapal yang kamar mesin (engine room) berada di bagian belakang kapal, memiliki kerugian mekanis sebesar 2\%, untuk kapal Mini LNG ini, kamar mesin direncanakan diletakkan pada bagian belakang, sehingga untuk menghitung kerugian mekanis dengan persamaan:

$$
\text { SHP }=\text { DHP } / 0.98
$$

7. Power Main Engine (BHP mcr)

Adalah besarnya daya output dari motor penggerak propulsi kapal pada kondisi continues service rating (CSR), yaitu daya motor pada kondisi $80-85 \%$ dari maximum continues rating (MCR). Artinya daya yang dibutuhkan oleh kapal agar mampu beroperasi dengan kecepatan sevis (Vs) adalah cukup dengan 80-85\% dari daya mesin (engine rated power) dan pada kisaran 100\% putaran mesin (engine rated speed). Persamaan untuk menghitung BHPmcr adalah:

$$
\text { BHPmcr }=\text { BHPscr } / 0.85
$$

\section{HASIL DAN PEMBAHASAN}

\subsection{Hydrostatic Analysis}

Langkah pertama untuk melakukan analisa dengan menggunakan simulasi numeric berbasis Orca 3D adalah mencari Design Hydrostatic Analysis. Dimana untuk mempermudah penggunaan software Orca 3D mengikuti panduan yang dikeluarkan oleh [8]. Tampilan menu Design Hydrostatic ditampilkan pada gambar 3: 


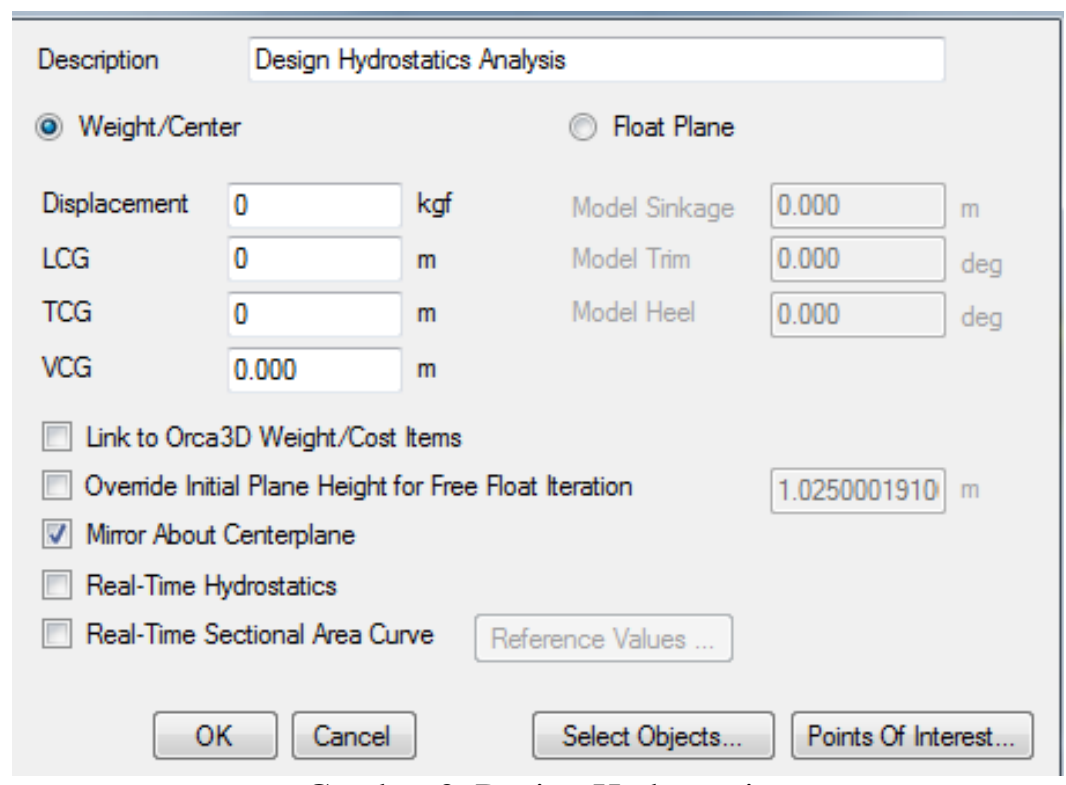

Gambar 3. Design Hydrostatic

Untuk inputan yang akan digunakan sebagai basis analisa hydrostatic dibagi menjadi 2, yaitu desain 1 dan desain 2 kapal Mini LNG. Untuk desain 1 dtampilkan pada tabel 3 dan desain 2 ditampilkan pada table 4.

Tabel 3. Input design hydrostatic kapal Mini LNG desain 1

\begin{tabular}{lll}
\hline Keterangan & Ukuran & Unit \\
\hline Displacement $(\Delta)$ & 1081.65 & $\mathrm{~m}$ ton \\
LCG & 21.09 & $\mathrm{~m}$ \\
TCG & 0.00 & $\mathrm{~m}$ \\
VCG & 2.57 & $\mathrm{~m}$ \\
\hline
\end{tabular}

Tabel 4. Input design hydrostatic kapal Mini LNG desain 2

\begin{tabular}{lll}
\hline Keterangan & Ukuran & Unit \\
\hline Displacement $(\Delta)$ & 5765.56 & $\mathrm{~m}$ ton \\
LCG & 41.77 & $\mathrm{~m}$ \\
TCG & 0.00 & $\mathrm{~m}$ \\
VCG & 4.27 & $\mathrm{~m}$ \\
\hline
\end{tabular}

Setelah inputan data kapal dimasukkan, maka didapatkan data hydrostatic kapal Mini LNG, untuk desain 1 ditampilkan pada gambar 4 dan untuk desain 2 ditampilkan pada gambar 5.

\begin{tabular}{|c|c|c|c|c|}
\hline \multicolumn{3}{|c|}{ Resulting Model Attitude and Hydrostatic Properties } & & \\
\hline Condition & Sinkage $(\mathrm{m})$ & Trim(deg) & Heel(deg) & $\operatorname{Ax}\left(m^{\wedge} 2\right)$ \\
\hline
\end{tabular}

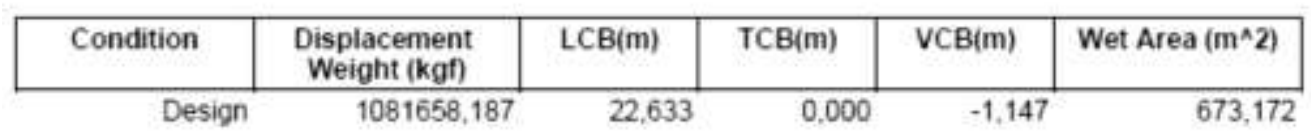

\begin{tabular}{|r|r|r|r|r|}
\hline Condition & \multicolumn{1}{|c|}{$\operatorname{Awp}\left(\mathrm{m}^{\wedge} \mathbf{2}\right)$} & LCF $(m)$ & TCF $(m)$ & \multicolumn{1}{c|}{ VCF $(m)$} \\
\hline Design & 513,093 & 21,653 & 0,000 & 0,000
\end{tabular}

\begin{tabular}{|c|c|c|c|c|}
\hline Condition & BMt(m) & BMI(m) & GMt(m) & GMl(m) \\
\hline Design & 5,101 & 82,718 & None Available & None Available
\end{tabular}

\begin{tabular}{|c|c|c|c|c|c|c|}
\hline Condition & $\mathrm{Cb}$ & $\mathrm{Cp}$ & $\mathrm{Cwp}$ & $\mathrm{Cx}$ & Cws & Cvp \\
\hline Design & 0,793 & 0,803 & 0,965 & 0,987 & 3,035 & 0,822
\end{tabular}

Gambar 4. Hydrostatic kapal Mini LNG desain 1

copyright is published under Lisensi Creative Commons Atribusi 4.0 Internasional. 


\begin{tabular}{|c|c|c|c|r|}
\hline Resulting Model Artitude and Hydrostatic Properties & \\
\hline Condition & Sinkage (m) & Trim(deg) & Heel(deg) & Ax(m^2) \\
\hline
\end{tabular}

\begin{tabular}{|c|c|c|c|c|r|}
\hline Condition & $\begin{array}{c}\text { Displacement } \\
\text { Weight (kgf) }\end{array}$ & LCB $(\mathrm{m})$ & $\mathrm{TCB}(\mathrm{m})$ & $\mathrm{VCB}(\mathrm{m})$ & Wet Area $\left(\mathrm{m}^{\wedge} \mathbf{2}\right)$ \\
\hline
\end{tabular}

\begin{tabular}{|c|r|r|r|r|}
\hline Condition & Awp $\left(m^{\wedge} 2\right)$ & LCF $(m)$ & \multicolumn{1}{c|}{ TCF $(m)$} & \multicolumn{1}{c|}{ VCF $(m)$} \\
\hline Design & 1684,721 & 41,842 & 0,000 & 0,000
\end{tabular}

\begin{tabular}{|c|c|c|c|c|c|c|}
\hline Condition & BMt(m) & BMl(m) & GMtim) & \multicolumn{1}{c|}{ GMi(m) } \\
\hline Design & 9,542 & None Available \\
\hline Condition & Cb & Cp & Cwp & Cx & Cws & Cvp \\
\hline Design & 0,764 & 0,769 & 0,870 & 0,993 & 3,043 & 0,878
\end{tabular}

Tabel 5. Hydrostatic kapal Mini LNG desain 2

\subsection{Speed/Power Analysis}

Dari hasil hydrostatic kapal mini LNG, maka berikutnya adalah melakukan analisa prediksi tahanan dan propulsi kapal Mini LNG sesuai dengan standar yang ditetapkan oleh [9] dan telah banyak digunakan untuk menganalisa tahanan dan propulsi kapal. Untuk kecepatan kapal yang didesain untuk desain 1 dan desain 2 dibuat sama dengan inputan kecepatan minimum, maksimum dan dinas,masing-masing 5 knot, 12 knot, 10 knot dan 1 knot.

\subsection{Sea Margin}

Sea margin adalah besaran yang dimasukkan sebagai kompensasi dari pengaruh lingkungan pada saat kapal berlayar seperti angin, arus dan gelombang. Menurut [10] pada papernya menyatakan untuk kapal yang berlayar memiliki sea margin berkisar 10-30\% tergantung dari jenis kapal dan rute pelayaran. Untuk paper ini sea margin yang dipilih sebesar 15\% dengan efisiensi propulsi dengan memperhitungkan $85 \%$ BHPmcr dengan tampilan sebagai berikut.

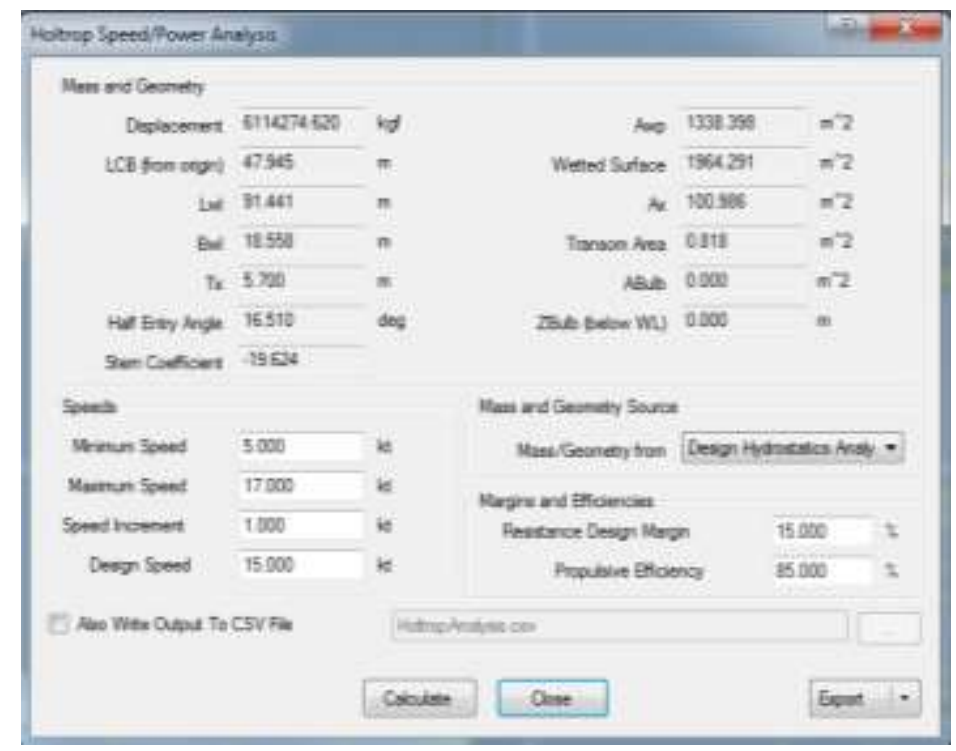

Gambar 6. Speed/Power Analysis

\subsection{Perhitungan Tahanan Kapal Mini LNG}

Perhitungan tahanan dilakukan menggunakan Orca 3D dilakukan setelah meng-inputkan parameter desain kapal yang akan dihitung pada menu speed/power analysis.

copyright is published under Lisensi Creative Commons Atribusi 4.0 Internasional. 
Untuk hasil perhitungan tahanan pada kapal Mini LNG desain 1 ditampilkan pada tabel 7.

Tabel 7. Perhitungan tahanan kapal Mini LNG desain 1

\begin{tabular}{lll}
\hline Kecepatan (Knot) & Fn & Rtotal $(\mathrm{kN})$ \\
\hline 5 & 0.120 & 10.01 \\
6 & 0.144 & 14.26 \\
7 & 0.168 & 20.64 \\
8 & 0.192 & 32.59 \\
9 & 0.216 & 56.59 \\
10 & 0.240 & 101.07 \\
11 & 0.265 & 184.32 \\
12 & 0.289 & 282.77 \\
\hline
\end{tabular}

Pada tabel 7 pada kolom pertama adalah kecepatan kapal (knot), kolom kedua adalah Froude number kapal (Fn) dan kolom ketiga adalah tahanan total kapal $(\mathrm{kN})$. Untuk kapal Mini LNG desain 2 hasil perhitungan tahanan kapal ditampilkan pada tabel 8.

Tabel 8. Perhitungan tahanan kapal Mini LNG desain 2

\begin{tabular}{lll}
\hline Kecepatan (Knot) & Fn & Rtotal $(\mathrm{kN})$ \\
\hline 5 & 0.085 & 73.22 \\
6 & 0.102 & 103.35 \\
7 & 0.119 & 137.97 \\
8 & 0.136 & 176.86 \\
9 & 0.216 & 219.89 \\
10 & 0.240 & 267.06 \\
11 & 0.265 & 318.52 \\
12 & 0.289 & 374.57 \\
\hline
\end{tabular}

Pada tabel 8 kolom pertama adalah kecepatan kapal (knot), kolom kedua adalah Froude number (Fn) dan kolom ketiga adalah tahanan total $(\mathrm{kN})$.

Untuk memperjelas hubungan antara kecepatan dan tahanan total pada desain 1 dan desain 2 maka dibuat grafik 1 .

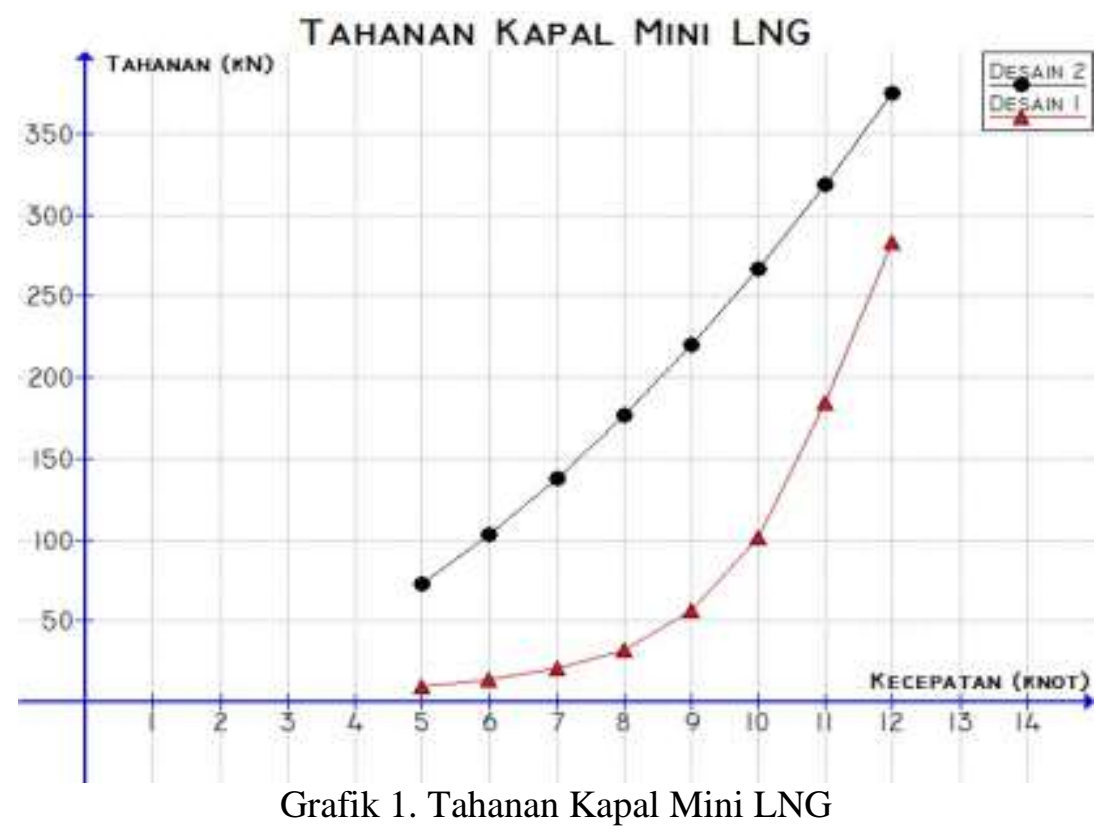




\subsection{Perhitungan EHP dan BHP Kapal Mini LNG}

Perhitungan EHP dan BHP dilakukan setelah melakukan input parameter kapal yang akan dihitung menggunakan Orca 3D. Untuk desain 1 EHP dan BHP kapal ditampilkan pada tabel 9.

Tabel 9. Perhitungan EHP dan BHP kapal Mini LNG desain 1

\begin{tabular}{lll}
\hline Kecepatan (Knot) & EHP $(\mathrm{kW})$ & BHP $(\mathrm{kW})$ \\
\hline 5 & 25.751 & 30.29 \\
6 & 44.004 & 51.77 \\
7 & 74.332 & 87.45 \\
8 & 134.116 & 157.78 \\
9 & 262.001 & 308.24 \\
10 & 519.932 & 611.68 \\
11 & 1043.051 & 1227.12 \\
12 & 1745.611 & 2053.66 \\
\hline
\end{tabular}

Sedangkan untuk EHP dan BHP kapal desain 2 disajikan pada tabel 10.

Tabel 10. Perhitungan EHP dan BHP kapal Mini LNG desain 2

\begin{tabular}{lll}
\hline Kecepatan (Knot) & EHP $(\mathrm{kW})$ & BHP $(\mathrm{kW})$ \\
\hline 5 & 188.349 & 221.59 \\
6 & 319.007 & 375.30 \\
7 & 496.858 & 584.54 \\
8 & 727.892 & 856.34 \\
9 & 1018.103 & 1197.77 \\
10 & 1373.877 & 1616.33 \\
11 & 1802.460 & 2120.54 \\
12 & 2312.336 & 2720.40 \\
\hline
\end{tabular}

Untuk memperjelas hubungan antara kecepatan dan EHP serta BHP untuk desain 1 dan desain 2 maka dibuat grafik 2 dan grafik 3.

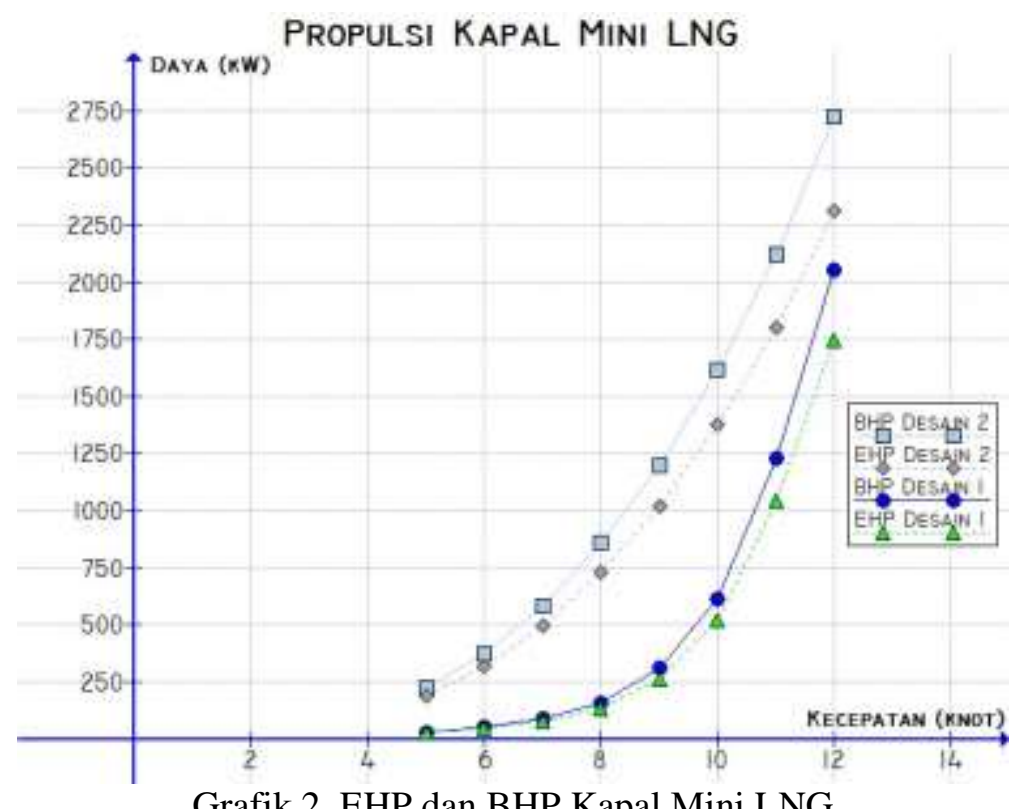

Grafik 2. EHP dan BHP Kapal Mini LNG

Setelah inputan data kapal dimasukkan, maka didapatkan data hydrostatic kapal Mini LNG, untuk desain 1 ditampilkan pada tabel 5 dan untuk desain 2 ditampilkan pada tabel 6. 


\section{KESIMPULAN}

Kesimpulan yang didapat dari hasil perhitungan tahanan dan propulsi kapal Mini LNG pada paper ini adalah bahwa tahanan kapal desain 1 pada kecepatan servis 10 knot sebesar $101.01 \mathrm{kN}$, sedangkan tahanan kapal desain 2 pada kecepatan servis 10 knot sebesar $267.06 \mathrm{kN}$. Untuk perhitungan EHP dan BHP kapal dapat dipergunakan untuk meng-estimasi kebutuhan daya mesin yang akan dipasang pada kapal. Hail perhitungan untuk EHP kapal desain 1 pada kecepatan dinas 10 knot sebesar $519.93 \mathrm{~kW}$ dan BHP sebesar $611.68 \mathrm{~kW}$. Untuk desain 2 EHP sebesar $1373.87 \mathrm{~kW}$ dan BHP sebesar $1616.33 \mathrm{~kW}$. Dari grafik yang ditampilkan untuk kapal Mini LNG desain 1 tahanan kapal meningkat secara parabolic untuk kecepatan diatas 10 knot, sehingga bila kapal dioperasikan pada kecepatan maksimum 12 knot maka diperlukan kapasitas engine diatas $2100 \mathrm{~kW}$, sedangkan untuk desain 2 bila dioperasikan pada kecepatan maksimum 12 knot diperlukan kapasitas engine diatas $2700 \mathrm{~kW}$.

\section{DAFTAR PUSTAKA}

[1] J. Maritim, "Small LNG Tanker dan Aplikasinya di Indonesia," 2017. https://jurnalmaritim.com/small-lng-tanker-dan-aplikasinya-di-indonesia/.

[2] E. Bøckmann and S. Steen, "Model test and simulation of a ship with wavefoils," Appl. Ocean Res., vol. 57, pp. 8-18, 2016, doi: 10.1016/j.apor.2016.02.002.

[3] M. Terziev, T. Tezdogan, and A. Incecik, "A geosim analysis of ship resistance decomposition and scale effects with the aid of CFD," Appl. Ocean Res., vol. 92, no. September, pp. 1-17, 2019, doi: 10.1016/j.apor.2019.101930.

[4] J. R. Saripilli and D. Sen, "Numerical studies on effects of slosh coupling on ship motions and derived slosh loads," Appl. Ocean Res., vol. 76, no. April, pp. 71-87, 2018, doi: 10.1016/j.apor.2018.04.009.

[5] A. S. Mujahid and K. Priohutomo, "Studi Kelayakan Desain Kapal Hisap Tambang," Wave J. Ilm. Teknol. Marit., vol. 12, no. 2, pp. 81-88, 2018, doi: 10.29122/jurnalwave.v12i2.3461.

[6] G. Regatama, W. Amiruddin, and I. P. Mulyatno, "Studi Perancangan Kapal LNG 3150DWT," Tek. Perkapalan, vol. 7, no. 2, pp. 152-160, 2017.

[7] J. Holtrop and G. . Mennen, "An Approximate Power Prediction Method," MARIN, no. 1982, pp. 166170, 1982.

[8] D. Technology, Orca 3D User Manual, 1.3.5., vol. 1.3.5, no. January. 2017.

[9] R. P. and G. ITTC, "Predicting Powering Margins," ITTC, vol. 7.5-02, no. 03-01.5, pp. 1-10, 2017.

[10] E. V. Lewis, Principles of Naval Architects - Resistance, Propulsion and Vibration, vol. II. The Society of Naval Architects and Marine Engineer, 1988. 